\title{
SAFETY AND EFFICACY OF HEPARIN-BONDED SURFACES IN CARDIOPULMONARY BYPASS*
}

\author{
Ludwig K. von Segesser, MD, FETCS, FACS
}

$T^{h}$ he first article on heparin surface bonding was published in 1963 by Gott, Whiffen, and Datton. ${ }^{1}$ At that time, the development of blood-exposed surfaces with improved thromboresistance was of prime interest. In those days, device occlusion during cardiopulmonary bypass (CPB) was a current problem. The presence of a shunt line that allows the arterial filter to be bypassed in most CPB circuits is still a testament to this major weakness of perfusion. Fortunately, in the early days the arterial filters tended to thrombose before the heat exchangers and oxygenators, and bypassing them usually salvaged the procedure. However, increasing awareness of this problem led to the development of more thromboresistant arterial filters with a variety of heparin surface coatings. The success of these efforts opened the door for systematic application of heparin surface coatings for filter screens at various positions in the CPB circuit. Routine clinical use of heparin-coated components was thus established. The practice remained unrecognized for many years because CPB appeared to be extremely safe in conjunction with full systemic heparinization as defined by an activated coagulation time (ACT) of more than 480 seconds.

Use of heparin-coated equipment for perfusion with low or no systemic heparinization again goes back to Gott, who introduced the Gott shunt for bypassing blood during repair of aneurysms of the descending thoracic aorta. This approach, which was adopted by many surgeons, provided evidence that perfusion devices did not require full systemic heparinization if their design and surface properties were adequate. However, almost

\footnotetext{
*For related article, see p. 324.

From the Department for Cardiovascular Surgery, Centre Hospitalier Universitaire Vaudois, CHUV, Lausanne, Switzerland.

Received for publication Oct 2, 2000; accepted for publication Oct 19, 2000.

Address for reprints: L. K. von Segesser, MD, FETCS, FACS, Department for Cardiovascular Surgery, Centre Hospitalier Universitaire Vaudois, CHUV, Rue du Bugnon 46, CH-1011 Lausanne, Switzerland

(E-mail: Ludwig.von-Segesser@chuv.hospvd.ch).

J Thorac Cardiovasc Surg 2001;121:200-1

Copyright (C) 2001 by The American Association for Thoracic Surgery

0022-5223/2001 $\$ 35.00+0 \quad \mathbf{1 2 / 1 / 1 1 2 8 1 8}$

doi: $10.1067 / \mathrm{mtc} .2001 .112818$
}

30 years of step-by-step development ${ }^{2}$ were necessary to get access to the tip-to-tip heparin-coated CPB circuit that allowed, first, partial and, later, total $\mathrm{CPB}^{3}$ with low systemic heparin levels similar to those used in vascular surgery (ACT > 180 seconds). Even though a number of studies have demonstrated reduced blood loss and transfusion requirements after CPB with heparincoated equipment and low systemic heparinization, 4,5 this issue remains the subject of controversy.

In parallel, many groups documented that heparin surface coating of perfusion equipment reduced the perfusion-induced inflammatory response. ${ }^{6}$ These findings may be less striking in the clinical setting with full systemic heparinization, because of the significant noise level resulting from cardiotomy suction ${ }^{7}$ and other ancillary equipment. However, increasing evidence shows that heparin-coated perfusion equipment is beneficial, despite full systemic heparinization. Wahba and colleagues ${ }^{8}$ have demonstrated significant reduction of transoxygenator/heat exchanger pressure gradients for various heparin-coated devices as compared with uncoated devices during routine cardiac surgery. These findings suggest that the pressures between the main pump and the oxygenator/heat exchanger structure often reach critical levels in current clinical practice in which uncoated perfusion equipment is used. This phenomenon usually is unnoticed because the arterial pressure is not usually measured anterior to the oxygenator/heat exchanger structure. Obviously, routine CPB is still far from perfect.

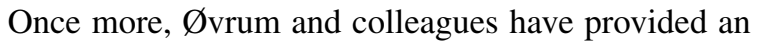
important piece of work in this setting. Their most recent study ${ }^{9}$ involves 1336 patients undergoing routine coronary bypass with either Duraflo II (Baxter Healthcare Corp, Bentley Laboratories Division, Irvine, Calif) or Carmeda BioActive Surface (CBAS; Medtronic Inc, Minneapolis, Minn) heparin-coated CPB equipment with low systemic heparinization (ACT $>250$ seconds). The 2 heparin coatings studied have very different histories, are chemically different, and are bonded differently. Baseline patient parameters and outcomes look similar for the 2 patient groups analyzed. The patients with Duraflo II-coated CPB equipment required less systemic heparin to maintain the target ACT than did the patients with CBAS-coated CPB 
equipment. Interestingly enough, patients in the Duraflo II group also required less protamine for neutralization of circulating heparin than did patients in the CBAS group. The authors suggest that heparin leakage from the Duraflo II coating, which is more common than leakage from the CBAS coating, can explain this finding. However, if free heparin originating from the coating would have to be neutralized together with injected heparin, thus completing the total amount of circulating heparin necessary to reach a certain target ACT, one would expect to see no difference for protamine requirements between the 2 groups analyzed. Alternatively, a higher rate of antithrombin III adsorption onto the CBAS coating can explain higher requirements for both circulating heparin and then protamine as compared with the Duraflo II group.

Other mechanisms are involved as well, but this theoretical discussion should not divert our attention from the fact that $\emptyset_{\text {vrum and colleagues }}{ }^{9}$ have operated on a substantial number of patients (1336) who underwent routine coronary bypass grafting with low systemic heparinization and no oxygenator obstruction. Their achievements include $4.6 \pm 1.3$ distal anastomoses per patient, at least 1 internal thoracic artery anastomosis in $99.3 \%$ of the patients, homologous transfusions in only $4.3 \%$ of the patients, and a hospital mortality of $0.3 \%$ (4/1336 patients)! If this was the standard of care on January 1, 2000, the rest of us doing CPB operations, as well as those involved in blood banking, are facing a major challenge.

Of course, one has to be aware of the disadvantages of perfusion with low systemic heparinization despite the use of heparin-coated equipment (eg, potential for device occlusion, stroke) and the technical hints to avoid them. ${ }^{3}$ However, to give this approach a fair trial, one must also consider the disadvantages of full sys- temic heparinization (eg, bleeding, homologous transfusion, transfusion-related infection with regularly updated additional microorganisms). Hence, although the CPB philosophy selected for a specific patient (full versus low systemic heparinization) is a tradeoff, it becomes more and more apparent that, effectively, there is no free ride!

\section{REFERENCES}

1. Gott VL, Whiffen JD, Datton RC. Heparin surface bonding on colloidal graphite surface. Science 1963:142;1297-8.

2. von Segesser LK, Weiss BM, Turina MI. Perfusion with heparin-coated equipment: potential for clinical use. Sem Thorac Cardiovasc Surg 1990;2:373-80.

3. von Segesser LK, Weiss BM, Pasic M, Garcia E, Turina MI. Risk and benefit of low systemic heparinization during open heart surgery. Ann Thorac Surg 1994;58:391-8

4. Aldea GS, Doursounian BA, O'Gara P, Treanor P, Shapira OM, Lazar HL, et al. Heparin bonded circuits with a reduced anticoagulation protocol in primary CABG: a prospective, randomized study. Ann Thorac Surg 1996;62:410-8.

5. Øvrum E, Åm Holen E, Tangen G, Brosstad F, Abdelnoor M, Ringdal AML, et al. Completely heparinized cardiopulmonary bypass and reduced systemic heparin: clinical and hemostatic effects. Ann Thorac Surg 1995;60:365-71.

6. Videm V, Svennevig JL, Fosse E, Semb G, Østerud A, Mollnes TE. Reduced complement activation with heparin-coated oxygenator and tubings in coronary bypass operations. $\mathrm{J}$ Thorac Cardiovasc Surg 1992;103:806-13.

7. Tevaearai HT, Mueller XM, Horisberger J, Augstburger M, Bock $\mathrm{H}$, Knorr A, et al. In situ control of cardiotomy suction reduces blood trauma. ASAIO J 1998;44:M380-3.

8. Wahba A, Philipp A, Behr R, Birnbaum DE. Heparin coated equipment reduces the risk of oxygenator failure. Ann Thorac Surg 1998;65:1310-2.

9. Øvrum E, Tangen G, Øystese R, Ringdal MAL, Istad R. Comparison of two heparin-coated extracorporeal circuits with reduced systemic anticoagulation in routine coronary artery bypass operations. J Thorac Cardiovasc Surg 2001;121:324-30. 